\title{
兵庫県六甲花崗崖体中の $\mathrm{U}, \mathrm{Th}, \mathrm{K}$ の分布
}

\author{
Uranium, thorium and potassium content of Rokko \\ granitic bodies, Hyogo Prefecture.
}

\author{
西 村 進 (Susumu Nishimura)* \\ 桂 京 造 (Kyozo Katsura)**
}

\begin{abstract}
The distributions of uranium, thorium and potassium content are traced in Rokko granitic bodies. These radio-elements determined have a tendency to concentrate in coarse-grained biotite granite than fine-grained, especially as to uranium.

The following data are obtained: Rokko granite, $2.8 \mathrm{ppm} \mathrm{U;} 10.1 \mathrm{ppm}$

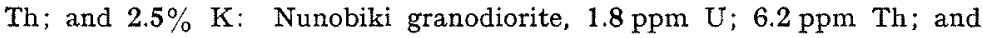
$1.4 \% \mathrm{~K}$ : Liparite, $2.2 \mathrm{ppm} \mathrm{U}$; $6.0 \mathrm{ppm} \mathrm{Th}$; and $3.1 \% \mathrm{~K}$.
\end{abstract}

\section{1. 序}

花岗岩体中の放射能分布については Gross (1947)；Ingham and Keevil (1951)； 初田 (1957); Nishimura (1951); Nishimura et al. (1965), またRaのみの分 布については Asayama (1936，1954) などの研究がある。これらの結果は大抵の場合, 逆入体の周边部に放射性元素の集中する傾向の強いことを示している。しかし，この一般 的傾向を乱すような份布もある。だが，今までに，U，Th，K の分布を同時に求めた研究 は非常に少ない。

今回，まず六甲花南岩体について U,Th，Kの分布を調べたのでここに報告する。

なお、この研究にあたり，御指導いただいた京都大学理学部初田甚一郎教授，大阪府立 大学教荃部浅山哲二教授に感謝する。

\section{2. 分析方 法}

U,Th の含有量は $\gamma$ 線エネルギー分析により (Nishimura et al., 1968 )， K の含有 量沽 $\beta$ 線の湘定によって (Katsura et al., 1969) 求めた。方法についてはこれらの報 告に詳しくのへているのでここでは省略する。なお，分析した試料のうち７試料について はRn法によってRa含有量をも求めた。

試料は答地点 (Fig. 1) より3〜4kg 程度，なるへく新鮮な岩石を採集して，粉砕し測定 に供した。

\footnotetext{
* 大阪府古大学教盖部地学教空

** 京都大学理学部地覚学銃物学教室
} 


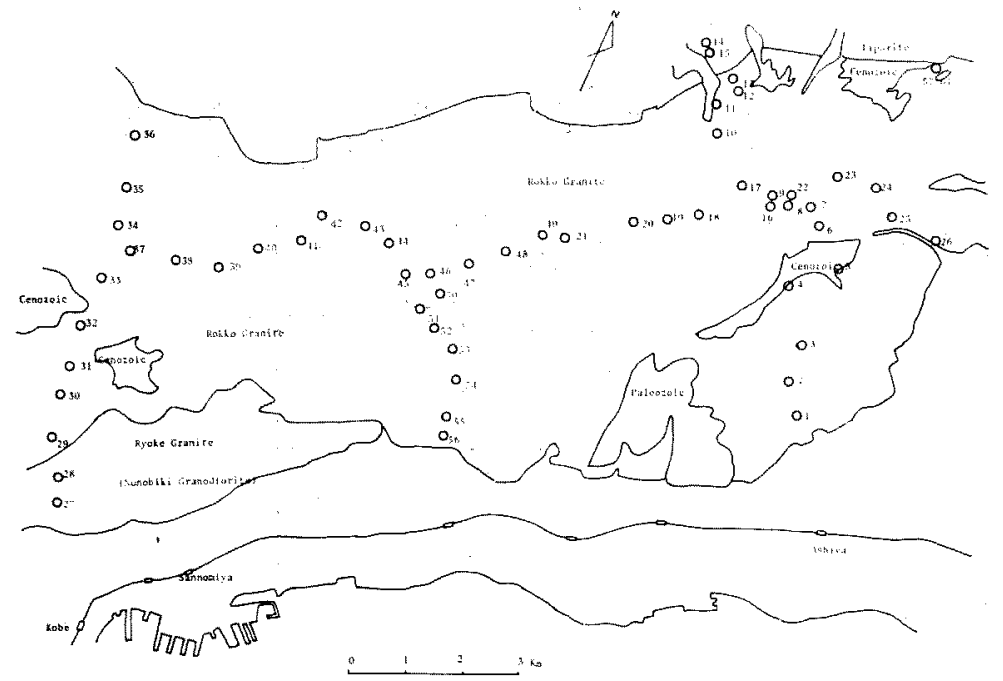

Fig. 1. Sampling site of Rokko granitic bodies

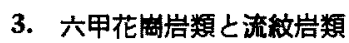

六甲花崗岩体の岩石学的研究はかなり良くなされている(本間，君塚，1928；上治， 1937 ; 藤田，笠間，1965)。それらの報告によると，六甲山地を作っている花凮岩類は 「布引花崗閃緑岩」と「六甲花菵岩」に分類される。

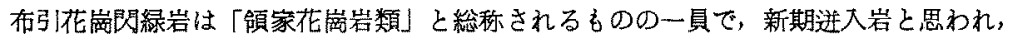
六甲山地南縁に露出している。この花崗聞緑岩は中粒完晶䝷で, 石英, 長石, 角既石, 黒 蛋寿より成り立っている。

六甲花髞岩は六甲山地の大部分を占めて分布しているもので中生代末に迸入したいわゆ る「中国底盤体」と呼ばれる巨大な花崗岩体の一部と考えられる。また，岩相の相違によ り，細粒，中粒，粗粒の三つの型に分類されるが，粗粒部々中粒部は互いに漸移する。主 要造岩鉱物は石英，長石，黒㞼母である。

流袮岩類は石英，長石の斑晶加淡緑色石基中に斑状に存在するちの，緻密で無斑晶，ま

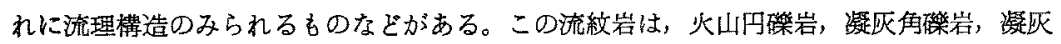
質頁岩，砂岩，磞岩の互層にはさまっていて一括して「有馬層群」と呼ばれる。またこ の有馬層群を貫く金剛童子流蒜岩が西部にみられる。

\section{4. 測 定 結 果}

Table 1 に得られた結果を示す。婇集した58陚料のうち放射平衡の成立しているもの は44，成立していないものは9試料であり，5武料についてはRa のみ测定した。

Table 1 で“0”型は放射平衡の成立していることを示し，“1”型は娘元 素の逸脱， “4”型はウラン元素の逸脱宗す（西村他，1966)。 
Table 1. Uranium, thorium and potassium content in rocks

\begin{tabular}{|c|c|c|c|c|c|c|c|c|}
\hline No. & Rock type & $\rho \widehat{\underline{\mathrm{a}}}$ & $=\widehat{E}$ & $\frac{8}{8}$ & 诺 & $\underset{H}{\stackrel{P}{F}}$ & $\frac{5}{4}$ & $\begin{array}{l}\text { Radioactive } \\
\text { equilibrium and } \\
\text { disequilibrium } \\
\text { type }\end{array}$ \\
\hline $\begin{array}{l}1 \\
2 \\
3 \\
4 \\
5\end{array}$ & $\begin{array}{c}\text { Biotite granite } \\
\text { " } \\
" \prime \\
" \prime\end{array}$ & $\begin{array}{l}3.4 \\
2.5 \\
3.1 \\
3.2\end{array}$ & $\begin{array}{r}9.2 \\
13.5 \\
14.1 \\
10.7 \\
9.5\end{array}$ & $\begin{array}{l}2.5 \\
2.9 \\
2.5 \\
2.8 \\
3.0\end{array}$ & 1.42 & $\begin{array}{l}2.7 \\
5.4 \\
4.5 \\
3.0\end{array}$ & $\left|\begin{array}{l}\times 10^{4} \\
0.74 \\
1.16 \\
0.81 \\
0.94\end{array}\right|$ & $\begin{array}{l}0 \\
0 \\
0 \\
4 \\
0\end{array}$ \\
\hline $\begin{array}{r}6 \\
7 \\
8 \\
9 \\
10\end{array}$ & $\begin{array}{l}\text { " } \\
\text { " } \\
\text { " }\end{array}$ & $\begin{array}{l}3.1 \\
4.8\end{array}$ & $\begin{array}{l}12.6 \\
15.2 \\
11.0 \\
14.9 \\
12.3\end{array}$ & $\begin{array}{l}2.3 \\
2.4 \\
2.9 \\
2.7 \\
2.9\end{array}$ & & $\begin{array}{l}3.5 \\
3.1\end{array}$ & $\begin{array}{l}0.94 \\
0.56\end{array}$ & $\begin{array}{l}0 \\
4 \\
0 \\
0 \\
4\end{array}$ \\
\hline $\begin{array}{l}11 \\
12 \\
14 \\
15 \\
16\end{array}$ & $\begin{array}{l}\qquad " \prime \\
\text { Liparite } \\
\text { Biotite granite }\end{array}$ & $\begin{array}{l}3.6 \\
4.5 \\
2.7 \\
3.0 \\
3.8\end{array}$ & $\begin{array}{r}16.4 \\
12.4 \\
9.6 \\
9.8 \\
14.8\end{array}$ & $\begin{array}{l}2.6 \\
3.7 \\
2.3 \\
3.0 \\
2.9\end{array}$ & 1.17 & $\begin{array}{l}4.5 \\
2.8 \\
3.6 \\
3.3 \\
3.9\end{array}$ & $\begin{array}{l}0.72 \\
0.82 \\
0.85 \\
1.00 \\
0.77\end{array}$ & $\begin{array}{l}0 \\
0 \\
0 \\
0 \\
0\end{array}$ \\
\hline $\begin{array}{l}17 \\
18 \\
19 \\
20 \\
21\end{array}$ & $\begin{array}{c}" \prime \\
\text { Granite porphyry } \\
\text { Fine-grained bi.gr. } \\
\text { " }\end{array}$ & \begin{tabular}{l|}
2.7 \\
2.1
\end{tabular} & $\begin{array}{r}13.5 \\
10.7 \\
7.7 \\
9.4 \\
8.7\end{array}$ & $\begin{array}{l}3.1 \\
3.1 \\
1.9 \\
2.2 \\
1.8\end{array}$ & & 4.1 & 0.70 & $\begin{array}{l}1 \\
4 \\
0 \\
4 \\
0\end{array}$ \\
\hline $\begin{array}{l}22 \\
23 \\
24 \\
25 \\
26\end{array}$ & $\begin{array}{c}\text { Biotite granite } \\
\text { " } \\
" 1 \\
"\end{array}$ & \begin{tabular}{l|}
3.2 \\
3.2 \\
3.7 \\
4.2 \\
3.3
\end{tabular} & $\begin{array}{r}9.8 \\
12.9 \\
13.4 \\
13.0 \\
10.0\end{array}$ & $\begin{array}{l}3.1 \\
3.1 \\
2.8 \\
3.1 \\
3.4\end{array}$ & & $\begin{array}{l}3.1 \\
4.0 \\
3.6 \\
3.1 \\
3.0\end{array}$ & $\begin{array}{l}0.00 \\
0.97 \\
0.97 \\
0.76 \\
0.74 \\
1.03\end{array}$ & $\begin{array}{l}0 \\
0 \\
0 \\
0 \\
0\end{array}$ \\
\hline $\begin{array}{l}27 \\
28 \\
30 \\
31 \\
32\end{array}$ & $\begin{array}{c}\text { Hornblende biotite gr. } \\
\text { " } \\
\text { Biotite granite } \\
\text { " }\end{array}$ & \begin{tabular}{l|}
2.3 \\
1.3 \\
4.7 \\
3.0
\end{tabular} & $\begin{array}{r}8.0 \\
4.3 \\
5.2 \\
13.5 \\
9.5\end{array}$ & $\begin{array}{l}1.2 \\
1.5 \\
1.6 \\
3.5 \\
2.9\end{array}$ & & $\begin{array}{l}2.9 \\
3.2\end{array}$ & $\begin{array}{l}0.74 \\
0.97\end{array}$ & $\begin{array}{l}0 \\
0 \\
0 \\
4 \\
0 \\
0\end{array}$ \\
\hline $\begin{array}{l}33 \\
34 \\
36 \\
37 \\
38\end{array}$ & $\begin{array}{l}" \prime \\
n \\
n \\
" \\
"\end{array}$ & \begin{tabular}{l|}
2.2 \\
1.9 \\
2.2 \\
3.7 \\
2.2
\end{tabular} & $\begin{array}{r}9.3 \\
6.1 \\
8.3 \\
10.2 \\
10.1\end{array}$ & $\begin{array}{l}2.0 \\
2.1 \\
1.6 \\
2.9 \\
2.4\end{array}$ & & $\begin{array}{l}4.2 \\
3.2 \\
3.8 \\
2.8 \\
4.5\end{array}$ & $\left|\begin{array}{l}0.91 \\
1.11 \\
0.73 \\
0.78 \\
1.09\end{array}\right|$ & $\begin{array}{l}0 \\
0 \\
0 \\
0 \\
0\end{array}$ \\
\hline $\begin{array}{l}39 \\
40 \\
41 \\
42 \\
43\end{array}$ & $\begin{array}{l}" \prime \\
n \\
\prime \prime \\
\prime \prime \\
"\end{array}$ & \begin{tabular}{l|l|}
3.3 & \\
2.7 & \\
1.8 & \\
2.4 & \\
2.3 &
\end{tabular} & $\begin{array}{r}11.7 \\
9.2 \\
5.3 \\
8.1 \\
7.9\end{array}$ & $\begin{array}{l}3.0 \\
2.3 \\
1.9 \\
2.2 \\
2.4\end{array}$ & & $\begin{array}{l}3.5 \\
3.4 \\
2.9 \\
3.4 \\
3.4\end{array}$ & $\begin{array}{l}0.91 \\
0.85 \\
1.06 \\
0.92 \\
1.04\end{array}$ & $\begin{array}{l}0 \\
0 \\
0 \\
0 \\
0\end{array}$ \\
\hline $\begin{array}{l}44 \\
45 \\
46 \\
47 \\
48\end{array}$ & $\begin{array}{l}\text { " } \\
\text { " } \\
\text { " }\end{array}$ & $\begin{array}{l}3.0 \\
2.2 \\
2.6 \\
2.0\end{array}$ & $\begin{array}{l}7.6 \\
8.0 \\
9.0 \\
4.2 \\
9.0\end{array}$ & $\begin{array}{l}2.3 \\
2.1 \\
2.5 \\
1.2 \\
2.1\end{array}$ & & $\begin{array}{l}2.5 \\
3.6 \\
3.3 \\
4.5\end{array}$ & $\begin{array}{l}0.77 \\
1.05 \\
0.93 \\
1.05\end{array}$ & $\begin{array}{l}0 \\
0 \\
0 \\
4 \\
0\end{array}$ \\
\hline $\begin{array}{l}49 \\
50 \\
51 \\
52 \\
53\end{array}$ & $\begin{array}{c}" \prime \prime \\
" \prime \\
\text { Fine-grained bi. gr. }\end{array}$ & $\begin{array}{l}2.9 \\
2.0 \\
2.2 \\
1.2\end{array}$ & $\begin{array}{r}9.5 \\
13.0 \\
7.1 \\
8.5 \\
4.4\end{array}$ & $\begin{array}{l}2.0 \\
4.0 \\
1.7 \\
2.0 \\
1.2\end{array}$ & & $\begin{array}{l}3.6 \\
3.7 \\
3.7\end{array}$ & $\begin{array}{l}0.85 \\
0.91 \\
1.00\end{array}$ & $\begin{array}{l}0 \\
1 \\
0 \\
0 \\
0\end{array}$ \\
\hline
\end{tabular}




\begin{tabular}{|c|c|c|c|c|c|c|c|c|}
\hline No. & Rock type & $p$ 㤩 & E高 & $\frac{\widehat{g}}{2}$ & $\stackrel{\overparen{D D}}{\stackrel{\Delta D}{\Xi}}$ & $\stackrel{P}{2}$ & $\sum_{1}^{2}$ & $\begin{array}{l}\text { Radioactive } \\
\text { equilibrium and } \\
\text { disequilibrium } \\
\text { type }\end{array}$ \\
\hline $\begin{array}{l}54 \\
55 \\
56 \\
57 \\
58 \\
59 \\
60 \\
61\end{array}$ & $\begin{array}{l}\text { Fine-grained bi.gr. } \\
\text { Biotite granite } \\
\qquad ", \\
\text { Liparite " }\end{array}$ & $\begin{array}{l}1.6 \\
1.8 \\
1.3\end{array}$ & $\begin{array}{l}4.9 \\
6.2 \\
5.8\end{array}$ & $\begin{array}{l}2.0 \\
2.2 \\
1.7\end{array}$ & $\begin{array}{l}2.57 \\
1.49 \\
1.19 \\
4.18 \\
1.20\end{array}$ & $\begin{array}{l}3.1 \\
3.4 \\
4.5\end{array}$ & $\begin{array}{l}\times 10^{4} \\
1.25 \\
1.22 \\
1.31\end{array}$ & $\begin{array}{l}0 \\
0 \\
0\end{array}$ \\
\hline
\end{tabular}

Table 2. Uranium, thorium and potassium content in rock types

\begin{tabular}{l|r|r|r|r|r}
\hline \multicolumn{1}{c|}{ Rock type } & $\begin{array}{c}\mathrm{U} \\
(\mathrm{ppm})\end{array}$ & $\begin{array}{c}\mathrm{Th} \\
(\mathrm{ppm})\end{array}$ & $\mathrm{K}(\%)$ & $\mathrm{Th} / \mathrm{U} \mathrm{K} / \mathrm{U}$ \\
\hline Rokko granite & & & & & $\times 10^{4}$ \\
$\quad$ Coarse-grained biotite granite & $3.5 \pm 0.1$ & $11.4 \pm 0.4$ & $2.8 \pm 0.1$ & 3.3 & 0.80 \\
Medium-grained biotite granite & $2.5 \pm 0.1$ & $8.9 \pm 0.4$ & $2.4 \pm 0.1$ & 3.6 & 0.96 \\
$\quad \begin{array}{l}\text { Fine-grained biotite granite } \\
\text { Nunobiki granodiorite }\end{array}$ & $1.6 \pm 0.1$ & $6.0 \pm 0.9$ & $1.7 \pm 0.2$ & 3.8 & 1.06 \\
Arima groups & $1.8 \pm 0.3$ & $6.2 \pm 1.2$ & $1.4 \pm 0.1$ & 3.4 & 0.78 \\
$\quad$ Liparite & 3.0 & 9.8 & 3.0 & 3.3 & 1.00 \\
Kongodoji-liparite & $2.2 \pm 0.4$ & $6.0 \pm 0.7$ & $3.2 \pm 0.4$ & 2.7 & 1.45 \\
\hline
\end{tabular}

測定結果をみると，岩体中の位置と各故射性元素の量との関係は明確ではないが，岩相

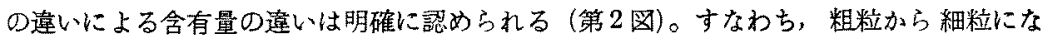
るにしたがって，各放射性元菜の含有量は減少する。また，Th/U，K/Uはともに增大 する。

六甲花崗岩体の平均では，U, Th, K 量はそれぞれ，2.8ppm；10.1ppm；2.5\%で， 岩石発熱量に換算*すると $4.3 \times 10^{-6} \mathrm{cal} / \mathrm{g} \cdot \mathrm{y}$ である。布引花峝岩体は $1.8 \mathrm{ppm}$; $6.2 \mathrm{ppm} ; 1.4 \%$ で, その発蠜量は $2.7 \times 10^{-6} \mathrm{cal} / \mathrm{g} \cdot \mathrm{y}$ である。さらに，流紋岩（金剛童 子流紋岩を含めて）は $2.2 \mathrm{ppm} ； 6.0 \mathrm{ppm} ; 3.196$ で, $3.0 \times 10^{-6} \mathrm{cal} / \mathrm{g} \cdot \mathrm{y}$ である。各岩 体の比較検討は，現在次々と測定を進めているので，後日総括して報告したい。

\section{引用 文 䓟}

Asayama, T. (1936), Radioaktive Untersuchung des Hiei Granitgebiets, Jap. Jour. Astro. Geophys., 14, 19 26.

Asayama, T. (1954), The radium content and the chemical composition of

*岩石発熱量は次式によって求めた。

$\mathrm{H}=\left(0.75^{238} \mathrm{U}+0.203^{232} \mathrm{Th}+0.05 \mathrm{~K}\right) \times 10^{-6}$ (cal/g.y.).ただし, U, Thは ppm で，K は9で表わす。 


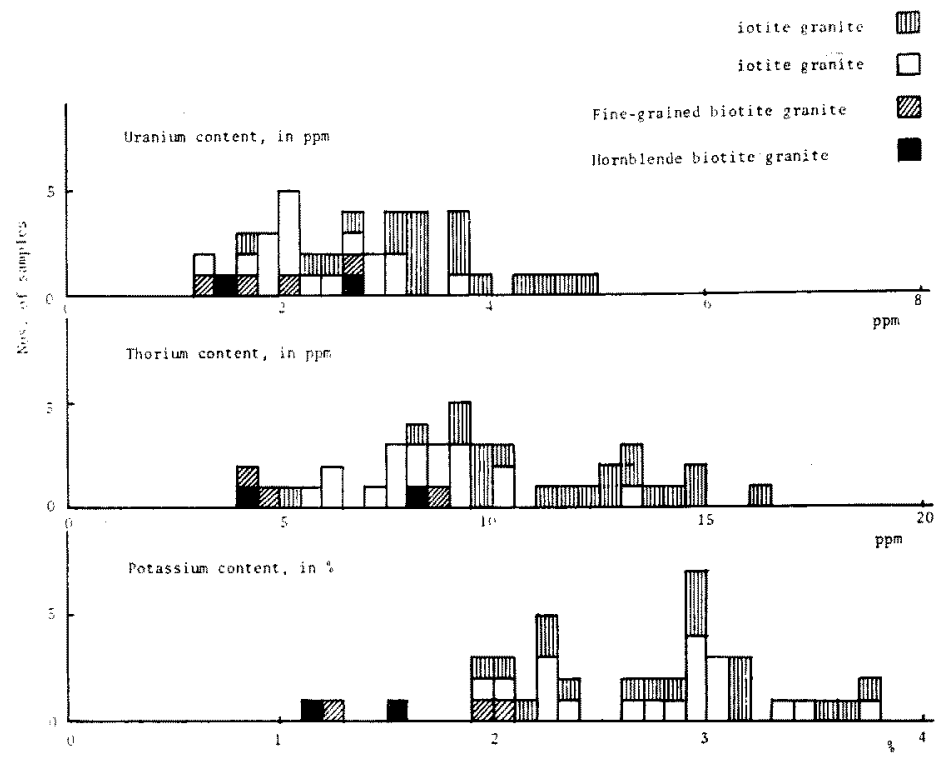

Fig. 2. The frequency of $U, T h$ and $K$ in granitic rocks of each mass.

granitic rocks in Japan, especially in the Tanakami-Mikumo and the Hiei regions, Siga and Kyoto Prefectures, Mem. Coll. Sci., Kyoto Tech. Univ., B, 25 54.

藤田 和夫，笠間 太郎 (1965)，西宫市およびその周縁の地質（西宫市 2 万 5 千分 の 1 地筫図説明書)，西宮市.

Gross, W.H. (1947), Radioactivity as a guide to Ore, Econ. Geol., 92, $722 \sim 742$.

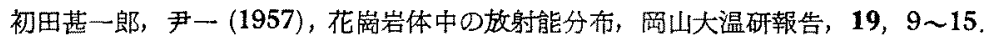

Ingham, W. H. and Keevil, H. B. (1951), Radioactivity of the Bourlamaque, Elzevir and Cheddar Batholiths, Geol. Soc. Am. Bull., 62, $131 \sim 148$.

Katsura, K., Nishimura, S., Yagi, S., Hatuda, Z. and Asayama, T. (1969), Uranium, thorium and potassium content of rocks in Japan (3), Rocks from Kyushu district, (in press).

Nishimura, S. (1962), The relationships between the petrology and the radioactivity of some granitic bodies (1), Mem. Coll. Sci, Univ. Kyoto, B, 29, 263 290.

Nishimura, S., Katsura, K. and Kusakari, H. (1965), The relations beween the petrology and the radioactivity of some granitic bodies (2), Mem. Coll. Sci., Univ. Kyoto, B, 31, 239 254.

西村 進, 初田甚一郎, 浅山㫪二 (1966), 放射能測定による岩石の U, Th の定量 (その 2), Radioisotopes, 15, 289 294. 
Nishimura, S., Yagi, S., Katsura, K., Hatuda, Z. and Asayama, T. (1968), Uranium, thorium and potassium content of rocks in Japan (1), Rocks from Chugoku district., Jour. Jap. Assoc, Min. Pet. Econ. Geol., 59, 206 213.

上治寅次郎 (1937)，六甲山塊の地筫と構造，地質雑，49,584. 